UNA RELACIÓN ENTRE CARTAS CRÉDITO Y LOGÍSTICA INTERNACIONAL

Revista Economía y Administración, Vol. 9, No. 22018

\title{
UNA RELACIÓN ENTRE CARTAS CRÉDITO Y LOGÍSTICA INTERNACIONAL
}

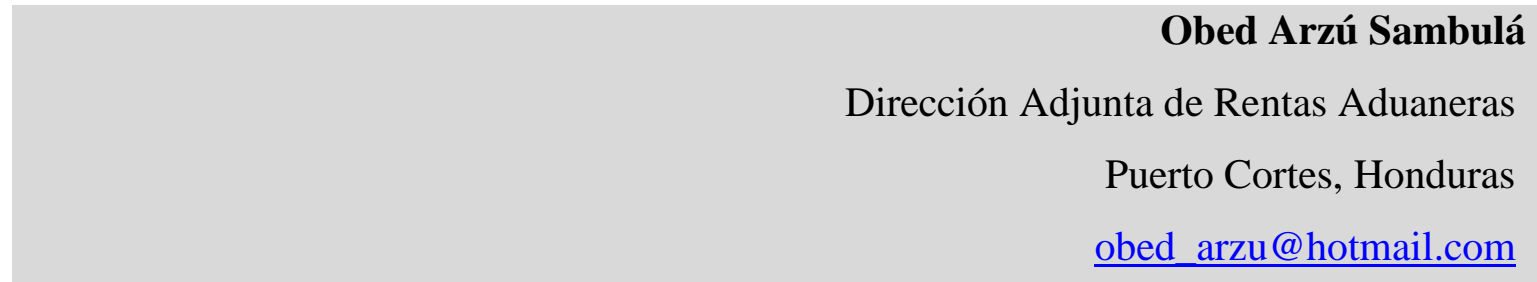

DOI: http://dx.doi.org/10.5377/eya.v9i2.6659

\section{RESUMEN}

Dado a que la globalización contribuye a que el comercio internacional sea cada vez más complejo, se ha creado una creciente interconexión de actividades que sirven de eslabón para unir las diferentes aéreas de una empresa, trabajando estas en conjunto. Por ello nace la necesidad de desarrollar artículos como el presente, cuyo objetivo principal es exponer, de manera técnica/práctica la relación que existe entre el servicio financiero de cartas de crédito y la logística internacional. Dos actividades centrales y de rápido cambio y crecimiento.

Documentación (como elemento principal), Incoterms, otros servicios, como el aseguramiento de las mercancías y el proceso que se lleva a cabo desde la negociación de precios y cantidades hasta que las mismas llegan a su destino final y cómo estas actividades se interrelacionan, es de lo que trata el presente artículo.

Palabras clave: financiación, crédito, logística, internacional. 


\section{A RELATION BETWEEN LETTERS OF CREDIT AND INTERNATIONAL LOGISTICS}

\section{Obed Arzú Sambulá}

Dirección Adjunta de Rentas Aduaneras

Puerto Cortes, Honduras

obed_arzu@hotmail.com

\section{DOI: http://dx.doi.org/10.5377/eya.v9i2.6659}

\section{ABSTRACT}

As globalization contributes to the growing complexity of international trade, a growing interconnection of activities has been created that serves as a link to unite the different areas of a company, working together. That is why the need arises to develop articles such as the present, whose main objective is to expose, in a technicalpractical way, the relationship between the financial service of letters of credit and international logistics. Two core activities of rapid change and growth.
Documentation (as main element), Incoterms, other services, such as the insurance of the goods and the process that takes place from the negotiation of prices and quantities until they reach their destination and as these activities are interrelated, is what this article is about.

Key words: financing, credit, logistics, international. 


\section{UNA RELACIÓN ENTRE CARTAS CRÉDITO Y LOGÍSTICA INTERNACIONAL}

Revista Economía y Administración, Vol. 9, No. 22018

\section{INTRODUCCIÓN}

El comercio internacional se rige por distintas disciplinas, tales como la mercadotecnia internacional, economía internacional, relaciones internacionales, financiación de operaciones comerciales internacionales, logística internacional. Dichas subdivisiones no operan de manera aislada unas de otras, sino que en algunos procesos se relacionan entre sí, existiendo una interdependencia a tal punto que, en el caso de la financiación y la logística internacional se realizan trabajos en conjunto, que afectan de manera directa algunas de sus operaciones.

Cabe mencionar, que para efectos de este artículo se toma en cuenta, como transacción principal la compraventa de bienes [mercancías] y no de servicios, la logística internacional, que hace llegar la mercancía a destino, y la financiación, mediante el servicio de cartas de crédito como actividad secundaria, al facilitar los pagos de los importes por la compra y venta de mercancía.

\section{COMERCIO}

INTERNACIONAL

El comercio es una de las actividades que brindan realce a la globalización. Personas, empresas, países, regiones deben adaptarse para ser cada vez más competitivos, en este sentido.

Según Anaya [2010], el comercio internacional se rige por diversas operaciones:

1. Aspectos teóricos: hay 7 teorías principales en el comercio internacional, siendo estas la ventaja absoluta, la ventaja comparativa, el modelo HecksherOhlin, el modelo de diamante de Michael Porter, la integración económica, la política comercial internacional y la estructura económica mundial.

2. Aspectos técnicos: estos se dividen en 5 aéreas que son clasificación arancelaria, valoración aduanera, operación aduanera, la logística y el transporte internacional.

3. Aspectos administrativos: se divide en formas de establecimiento de precios de exportación y en las formas de pago de los insumos a importar. 
UNA RELACIÓN ENTRE CARTAS CRÉDITO Y LOGÍSTICA INTERNACIONAL

Revista Economía y Administración, Vol. 9, No. 22018

Las formas de pago pueden ser mediante cheque, giro bancario, orden de pago, cobranza internacional, cartas de crédito, etc.

4. Aspectos de mercado: en si son los diferentes métodos en la mercadotecnia internacional.

5. Aspectos legales: conjunto de ordenamientos a los que se someten las operaciones de comercio internacional, proveyéndolas de un marco de legalidad. Los ordenamientos pueden ser locales [de un país o región] e internacionales [a nivel mundial].

Aspectos financieros: estos se dividen en el tipo de cambio y formas de pago.

\section{FINANCIACIÓN [FINANCING]}

La financiación es un conjunto de actividades que producen cambios en tamaño y composición de los capitales propios y de los préstamos tomados por parte de una empresa. [Nunes, 2012]

Los servicios de financiación promueven la economía tanto de un país, como a nivel internacional, para lo cual las instituciones bancarias cuentan con servicios especializados para suplir las necesidades de financiación de sus clientes.

\section{Financiación de operaciones de comercio exterior}

En este caso se financian operaciones de producción y venta, por parte del exportador y de pago, por parte del importador. Según[Levy, 2003], estas operaciones se dividen en las siguientes:

- Financiación del exportador:

1. Desde que se recibe el pedido hasta que se entrega la mercancía, y que incluye básicamente el periodo de fabricación. A esta fase se le conoce como prefinanciación de exportaciones. No obstante, su financiación tan sólo suele solicitarse cuando la fabricación del pedido obligue al exportador a realizar fuertes desembolsos y tenga una duración considerable.

2. Conocido como postfinanciación de 


\section{UNA RELACIÓN ENTRE CARTAS CRÉDITO Y LOGÍSTICA INTERNACIONAL}

Revista Economía y Administración, Vol. 9, No. 22018

exportaciones, este cubre el

periodo desde que se

entrega la mercancía hasta

que se cobra, ya que

normalmente estas

operaciones no se cobran al

contado, sino que por

razones comerciales se

suele conceder al

importador cierto

aplazamiento en el pago.

- Financiación del importador: Tiene que pagar al contado y no dispone de los fondos: el importador tiene que pagar la compra en el momento de recibirla, pero él antes de poder venderla nuevamente tendrá que elaborarla $\mathrm{o}$, si se trata de un producto final, puede que le lleve algún tiempo su venta y su posterior cobro. Este periodo [el que se media entre el momento que tiene que pagar su compra y el momento que va a cobrar su posterior venta] es el que tratará de financiar.

La financiación representa un conjunto de actividades de servicio, utilizadas en todo el globo, para dinamizar las actividades de comercio internacional. Las instituciones bancarias ofrecen a las empresas diversos servicios para este rubro, entre ellos:

1. Cartas de crédito

2. Factoraje internacional

3. Garantías bancarias

4. Transferencias internacionales

5. Cobranzas internacionales

6. Opciones de tipo de cambio

7. Futuros. [Zorrilla, 2004]

\section{CARTAS DE CRÉDITO [LETTERS OF CREDIT]}

Los créditos documentarios o cartas de crédito[como se le conoce en Honduras]es un servicio que ofrecen las instituciones bancarias a nivel nacional e internacional. Para poder contratar dicho servicio y gozar de sus beneficios, tanto el solicitante [importador] como el beneficiario [exportador] deben cumplir con ciertos requisitos, asegurando el cumplimento de lo estipulado en los contratos de compraventa y en las especificaciones descritas en el crédito.

Los servicios de cartas de crédito están regulados por las Costumbres y Prácticas Uniformes para los Créditos 


\section{UNA RELACIÓN ENTRE CARTAS CRÉDITO Y LOGÍSTICA INTERNACIONAL}

Revista Economía y Administración, Vol. 9, No. 22018

Documentarios [UCP 600] ${ }^{1}$, de la Cámara

de Comercio Internacional. [Bac

Honduras, 2015].

Este servicio es muy utilizado cuando se inicia una nueva relación con un cliente y máxime si este se encuentra en un país muy distante, habiendo poco conocimiento de las regulaciones de aquel país. [Banco Davivienda, 2015].

La carta de crédito es el medio de pago más utilizado en el comercio internacional, ya que ofrece seguridad en las ventas internacionales, asegurando al exportador el pago de su operación.

\section{Variantes de las cartas de crédito}

Habrá que tener en cuenta que, dependiendo de la combinación de opciones, será el coste de la apertura de una carta de crédito. A continuación, se enlistan dichas variantes:

- Revocable e irrevocable:

- Revocable: después de su apertura y antes de haber procedido al pago, el

${ }^{1}$ Uniform Customs and Practice for Documentary Credit(UCPDC), publicación número 600. UCP 600 en su forma corta. Es la más reciente versión de las reglas sobre cartas de crédito, la cual es importador puede anularlo en cualquier momento, por lo que la seguridad que ofrece es muy reducida.

- Irrevocable: una vez abierta, está ya no se puede cancelar, lo que garantiza al exportador que, si la documentación presentada es correcta, va a cobrar su venta.

- Confirmada [confirmed]: en este caso un tercer banco [normalmente un banco internacional de primera fila] garantiza el cumplimiento del pago en el supuesto de que el banco del importador no lo hiciera.

- A la vista [at sight] y a plazo [payment term]:

- A la vista: el pago de la operación es al contado, por lo que al momento de que se presenta la documentación, el banco del importador procede al pago del monto al exportador.

preparada por la Comisión de Técnicas y Prácticas Bancarias, de la Cámara de Comercio Internacional. 


\section{UNA RELACIÓN ENTRE CARTAS CRÉDITO Y LOGÍSTICA INTERNACIONAL}

Revista Economía y Administración, Vol. 9, No. 22018

- A plazo: el pago de la operación es aplazado.

Una vez entregada la documentación hay que esperar al transcurso del plazo acordado entre importador, exportador importador, su banco para recibir el importe de la venta.

En Honduras, al igual que en otros países, es más utilizada la carta de crédito stand$b y^{2}$. Su funcionamiento, en relación con la carta de crédito simple es diferente:

- En la carta de crédito simple quien tiene la obligación de pagar es el banco que lo ha emitido, con independencia, de que el importador tenga saldos o no.

- En la carta de crédito stand-by es el importador el primer obligado al pago, y el banco que emite esta carta sólo tendrá que realizarlo si el importador incumple su obligación.[Levy, 2003]
En las cartas de crédito intervienen diferentes instituciones, las que operan en conjunto para llevar a cabo el proceso de compraventa internacional mediante la utilización de esta forma de pago.

\section{Actores en las cartas de crédito:}

1. Ordenante o solicitante [applicant]: es la empresa importadora o compradora, la cual solicita a su banco la apertura de la carta de crédito.

2. Beneficiario [beneficiary]: es la empresa exportadora y vendedora.

3. Banco emisor [issuing bank]: este es el banco del importador. Es el que hace el pago del importe y el que posterior a la venta recibe el pago del ordenante.

4. Banco notificador [advising bank]: es el banco del beneficiario, quien recibe el importe de la venta.

5. Banco confirmador [confirming bank]: en el caso de que se utilice la modalidad de carta de crédito confirmada, se contrata los servicios de esta entidad, la que al

(importador). La diferencia principal es que la carta de crédito es un mecanismo de pago y el crédito stand-by es una garantía bancaria que se utiliza, principalmente para cubrir obligaciones comerciales impagadas.
${ }^{2}$ Conocido también como Crédito Documentario Contingente, este es un instrumento de garantía que emite un banco para respaldar al beneficiario (exportador) en caso de incumplimiento de pago de una obligación contractual por el ordenante 
UNA RELACIÓN ENTRE CARTAS CRÉDITO Y LOGÍSTICA INTERNACIONAL

Revista Economía y Administración, Vol. 9, No. 22018

igual que las demás, recibe una comisión por sus servicios.

6. Empresa de entrega rápida [curier]: por medio de esta agencia, el banco notificador envía los documentos de la mercancía al banco emisor, para su posterior entrega al ordenante.

7. SWIFT: (Society for Worldwide Interbank

Financial

Telecommunication] [Sociedad para la Telecomunicación Global Interbancaria Financiera]). Sociedad creada por la Comunidad Internacional de Entidades Financieras, para la transmisión rápida, segura y efectiva de documentos, dinero y mensajes, bajo un sistema computacional de comunicaciones a nivel mundial. [SAP Business Run, 2015]

\section{LOGÍSTICA INTERNACIONAL [INTERNATIONAL LOGISTICS]}

Tomando en cuenta la globalización comercial, la logística internacional es una de las actividades más necesarias hoy en día. Esta se compone de una serie de métodos, técnicas, empresas y personal especializado, sistemas informáticos, páginas web, maquinarias e instrumentos.
Todo en constante mejora, para hacer llegar un bien desde el punto de despacho hasta su destino, procurando cumplir con las condiciones de tiempo y costos estipulados.

La logística busca administrar estratégicamente la adquisición, movimiento, almacenamiento de mercancía y el control de inventarios, así como todo el flujo de información asociado (vía telefónica, internet y documentos), a través de los cuales la organización y su canal de distribución se encauzan de modo tal que la rentabilidad presente y futura de la empresa es maximizada en términos de costos y efectividad. [Molins, 2011] pp.4

Las actividades de logística internacional son reguladas y promovidas por gobiernos, empresas y organismos internacionales, regionales [en el caso de Centroamérica] y nacionales. En Honduras, la Dirección Adjunta de Rentas Aduaneras [DARA] es el ente adscrito a la Secretaria de Estado en el Despacho de Finanzas [SEFIN], que controla el ingreso y salida de mercancías y medios de transporte por las aduanas, a 


\section{UNA RELACIÓN ENTRE CARTAS CRÉDITO Y LOGÍSTICA INTERNACIONAL}

Revista Economía y Administración, Vol. 9, No. 22018

su vez es la que recauda tributos en materia de comercio exterior. Sus acciones están amparadas bajo diferentes bases legales, como el Código Tributario y el Código Aduanero Uniforme Centroamericano $[\mathrm{CAUCA}]^{3} \quad \mathrm{y} \quad \mathrm{su}$ Reglamento $[\mathrm{RECAUCA}]^{4}$.

Los Auxiliares de la Función Pública Aduanera, son las personas naturales o jurídicas, públicas o privadas, que participan ante el Servicio Aduanero en nombre propio o de terceros, en la gestión aduanera. Estos pueden ser:

- Las agencias aduaneras [customs agencies]: es el Auxiliar autorizado para actuar habitualmente, en nombre de terceros en los trámites, regímenes y operaciones aduaneras, en su carácter de persona natural, con las condiciones y requisitos establecidos.

- Los depositarios aduaneros [customs deposits]: es el responsable ante el Servicio Aduanero, por la custodia y conservación temporal de las

\footnotetext{
${ }^{3}$ Es un instrumento legal, emitido bajo la dirección del Consejo de Ministros de integración Económica [COMIECO], que posee jurisdicción en los países de Centroamérica [Honduras, Guatemala, Nicaragua, El Salvador y Costa Rica],
}

mercancías, bajo el control y supervisión de la Autoridad Aduanera.

- Los transportistas aduaneros [shipping agencies]: es el Auxiliar encargado de las operaciones y los trámites aduaneros relacionados con la presentación ante el Servicio Aduanero, del medio de transporte y carga, a fin de gestionar su ingreso, tránsito o salida de las mercancías. El transportista será responsable directo ante el Servicio Aduanero, por el transporte de las mercancías [y en ocasiones de documentos] objeto de control aduanero, por cualquiera de los medios [terrestre, aéreo, marítimo o multimodal]. [CAUCA IV, 2008]

La Cámara de Comercio Internacional $[\mathrm{CCI}]$ es uno de los principales organismos que intervienen en el comercio internacional, mediante el establecimiento de normas e instrumentos que aseguran el

resultado del proceso de integración económica de esta región.

${ }^{4}$ Es en donde se dicta como proceder, tomando como base los artículos del CAUCA. 


\section{UNA RELACIÓN ENTRE CARTAS CRÉDITO Y LOGÍSTICA INTERNACIONAL}

Revista Economía y Administración, Vol. 9, No. 22018

justo $\mathrm{y}$ efectivo funcionamiento en las actividades de compraventa de bienes y servicios. Ejemplo de ello son los Incoterms, instrumento importante utilizado en la logística internacional.

\section{Incoterms 2010}

Desde 1936 la CCI se ha encargado de la elaboración y actualización de los Incoterms (International Commercial Terms) - [Términos Internacionales de Comercio], actualizándose cada 10 años, según los cambios que va experimentando el comercio internacional de mercancías. Actualmente se encuentran en vigor los Incoterms 2010, a ser modificados en el año 2020.

Las reglas Incoterms reflejan las normas de aceptación voluntaria por el exportador e importador, sobre la responsabilidad de cada uno en cuanto a costos, seguros, riesgos, entrega y recepción de la mercancía.

La Convención sobre Contratos para la Venta Internacional de Mercancías de las Naciones Unidas [CISG, U.N. Convention on Contracts for the International Sale of Goods] en su Parte III [Venta de las mercancía, artículos 25-88] describe el momento en que el riesgo sobre la mercancía se transfiere del vendedor [fabricante o no] al comprador [sea este el comprador final o no], pero reconoce que, en la práctica, la mayoría de las transacciones internacionales se rigen de acuerdo con las obligaciones reflejadas en los Incoterms.

Existen 11 diferentes Incoterms, los cuales se explican a continuación:

\section{Grupo E [Entrega directa a la salida]}

- $\quad$ EXW (Ex Works) [en fábrica]: El vendedor pone la mercancía a disposición del comprador en su fábrica, almacén, etc. Todos los gastos a partir de ese momento son por cuenta del comprador.

\section{Grupo F [Entrega indirecta, sin pago del transporte principal]}

\section{- FAS (Free Alongside Ship)} [franco al costado del buque]: El vendedor entrega la mercancía en el muelle pactado del puerto de carga convenido; esto es, al lado del barco.

- FOB (Free On Board) [franco a bordo]: El vendedor entrega la mercancía sobre el buque. El 
UNA RELACIÓN ENTRE CARTAS CRÉDITO Y LOGÍSTICA INTERNACIONAL

Revista Economía y Administración, Vol. 9, No. 22018

vendedor contrata el transporte a través de un embarcador o un consignatario, pero el coste del transporte lo asume el comprador.

- FCA (Free Carrier) [franco transportista]: El vendedor se compromete a entregar la mercancía en un punto acordado dentro del país del exportador, que pueden ser los locales de un embarcador, una estación ferroviaria, etc. Se hace cargo de los costes hasta que la mercancía está situada en ese punto convenido; entre otros, la aduana en el país de origen.

\section{Grupo C [Entrega indirecta, con pago} del transporte principal]

- CFR (Cost and Freight) [coste y flete]: El vendedor se hace cargo de todos los costes, incluido el transporte principal, hasta que la mercancía llegue al puerto de destino.

- CIF (Cost, Insurance and Freight) [coste, seguro y flete]: El vendedor se hace cargo de todos los costes, incluidos el transporte principal y el seguro, hasta que la mercancía llegue al puerto de destino. Aunque el seguro lo ha contratado el vendedor, el beneficiario del seguro es el comprador.

- CPT (Carriage Paid To) [transporte pagado hasta]: es igual que el CFR, solamente que para transporte multimodal.

- CIP (Carriageand Insurance Paid To) [transporte y seguro pagados hasta]: es igual que el CIF, solamente que para transporte multimodal.

Grupo D - [Entrega directa en la llegada]

- DAT (Delivered At Terminal) [entregado en terminal]: este se utiliza para todos los tipos de transporte. El vendedor se hace cargo de todos los costes, incluidos el transporte principal y el seguro [que no es obligatorio], hasta que la mercancía es descargada en la terminal convenida. También asume los riesgos hasta ese momento. 
UNA RELACIÓN ENTRE CARTAS CRÉDITO Y LOGÍSTICA INTERNACIONAL

Revista Economía y Administración, Vol. 9, No. 22018

- DAP (Delivered At Place) [entregado en un punto]: el Incoterm DAP se utiliza para todos los tipos de transporte. El vendedor se hace cargo de todos los costes, incluidos el transporte principal y el seguro [que no es obligatorio] pero no de los costes asociados a la importación, hasta que la mercancía se ponga a disposición del comprador en un vehículo listo para ser descargado. También asume los riesgos hasta ese momento.

- DDP (Delivered Duty Paid) [entregada derechos pagados]: El vendedor paga todos los gastos hasta dejar la mercancía en el punto convenido en el país de destino. El comprador no realiza ningún tipo de trámite. Los gastos de aduana de importación son asumidos por el vendedor. El tipo de transporte es polivalente/multimodal. [Solano, 2014]
INTERRELACIÓN ENTRE CARTAS DE CRÉDITO Y LOGÍSTICA INTERNACIONAL

La relación entre estas dos disciplinas se centra, principalmente en la emisión, transporte y custodia de la documentación emitida las empresas negociantes de la compra/venta de mercancías, así como las instituciones bancarias que entran en juego.

Al momento de solicitar la carta de crédito, el importador debe cumplir con ciertos requisitos, al igual que el exportador, al momento de recibir el pago, debiendo mostrar a su institución bancaria la documentación solicitada en el crédito, la cual debe ser presentada siguiendo una serie de requisitos generales enlistados en los artículos de la UCP 600. Las inconsistencias en los documentos podrían generar atraso o la imposibilidad de que la mercancía llegue a su destino final, por ello el énfasis en enumerar los requisitos generales a cumplir al momento de presentar dichos documentos. 


\section{UNA RELACIÓN ENTRE CARTAS CRÉDITO Y LOGÍSTICA INTERNACIONAL}

Revista Economía y Administración, Vol. 9, No. 22018

\section{Documentación}

Los documentos por presentar serán los que se especifiquen en la carta de instrucciones $^{5}$, adjunta a la carta de crédito. El pago al exportador se realiza contra entrega de los documentos que certifiquen la venta [factura], el embarque [documentos de embarque], la calidad, origen [certificado de origen], peso [certificado de peso], composición química o física. [Bustamante, 2011]pp.68

Los documentos, desde el punto de vista del crédito, pueden ser obligatorios $u$ opcionales.

\section{Documentos obligatorios}

Son los más importantes y los que ejercen propiedad sobre las mercancías, requiriendo la presentación de los mismos en aduana, para su ingreso al país de importación. Estos documentos son los que no deben faltar en el proceso tanto de compraventa como de contratación del servicio de carta de crédito, ya que sin ellos dichos procesos no se podría llevar a cabo:
- Factura comercial [Commercial invoice]: Esta da propiedad sobre la mercancía, al momento de que se retire de aduana. El Incoterm que este mencionado en el crédito debe concordar con el importe de la factura.

- Documento de transporte [Transport document]: Los documentos de transporte son extendidos por las empresas de transporte ${ }^{6}$, además certifican la fecha del embarque, la carga a bordo e indican, para efectos aduanales, a quien debe consignarse la mercancía. Según el art. 14, inciso $j$, de la UCP 600, cuando el crédito indique que la parte a consignar o a notificar en el documento de transporte será el importador, entonces el domicilio del mismo deberá detallarse en la parte a consignar o a notificar. En estos documentos se indica, también la modalidad del flete [pagado o por cobrar], lo cual

\footnotetext{
${ }^{5}$ En esta, el importador le específica a su banco, los documentos $\mathrm{y}$ formatos que debe enviarle el exportador.
}

\footnotetext{
${ }^{6}$ Agencias navieras en el caso de transporte marítimo, trasportistas, en el caso de transporte terrestre y líneas aéreas en el transporte aéreo.
} 
UNA RELACIÓN ENTRE CARTAS CRÉDITO Y LOGÍSTICA INTERNACIONAL

Revista Economía y Administración, Vol. 9, No. 22018

dependerá del Incoterm que se utilice en la compraventa.

- Documento de seguro y cobertura [Certificate of insurance]: es el documento que acredita el aseguramiento de la mercancía. Este es emitido por una empresa aseguradora.

\section{Documentos opcionales}

Son los que se el importador puede solicitar al exportador como requisito de pago, agregándole seriedad y confianza al proceso, pudiendo ser emitidos por el beneficiario o terceras partes, como secretarias, laboratorios certificados, etc.:

- Certificado de origen [Certifícate of origin]: este es un documento que certifica que una mercancía es originaria de determinado país. Es un resultado de los diferentes tratados y acuerdos comerciales tendientes a facilitar el comercio entre dos o más naciones. $\mathrm{Al}$ nacionalizarse una mercancía en el país de importación, el certificado de origen hace efectivo el goce de beneficios arancelarios que recibe un exportador e importador de países adscritos a determinado convenio comercial.
- Certificado o lista de peso [Certificate/ist of weight]: en la compraventa de mercancías, el importador debe cerciorarse de que la misma cumple con las características negociadas, en este caso, el peso. Pues este documento certifica dicha característica.

- Lista de empaque [Packing list]: este es un documento opcional que puede elegir incluir en su envío. A pesar de ser similar, no reemplaza a la Factura comercial, la cual es usada por la aduana para determinar derechos y cargos aduaneros. Debido a que la Lista de empaque no incluye información sobre el costo o el valor del contenido, se puede usar en aquellos casos donde el contenido se enviará a un tercero, tal como un cliente o proveedor. [UPS, 2016]

Además de los documentos mencionados, el importador puede solicitar otros certificados que, de acuerdo con las características de la mercancía y las condiciones de la compraventa, serán los siguientes: 


\section{UNA RELACIÓN ENTRE CARTAS CRÉDITO Y LOGÍSTICA INTERNACIONAL}

Revista Economía y Administración, Vol. 9, No. 22018

- Certificado de calidad - [Product safety and quality certification]

- Certificado de análisis [químico, físico, bacteriológico, radioactivo, etc.] - [Certificate of analysis]

- Certificado de sanidad [fito/zoosanitario] - [Certificate of sanity]: este se emite para mercancías de origen animal o vegetal. Para efectos de importación y del crédito, este documento es opcional, pero para la exportación de bienes de origen animal o vegetal, es obligatorio. [Bustamante, 2011]pp.94

\section{El control en los documentos de transporte}

Cuando el banco otorga un crédito documentario o carta de crédito a un ordenante, es permisible que a juicio del banco emisor, se requiera que la mercancía sirva como garantía de pago, disponiéndose, en consecuencia, que el documento de transporte se emita como consignado a la orden de dicho banco. Así, el banco emisor se asegura de la posesión [no la propiedad] de la mercancía hasta que el comprador le liquide a dicho banco la deuda principal, pagando al vendedor más los gastos y comisiones de los bancos. Si el comprador no realiza el pago, el banco emisor no le entregara el documento de embarque, y tomando en cuenta que este viene consignado a su nombre, estará en posibilidad de retirar la mercancía de la aduana y [posterior a un juicio ejecutivo mercantil podrá adquirir legalmente la propiedad de la mercancía], venderla o hacer uso de ella resarciéndose de casi todo el adeudo no cubierto por el ordenante.[Bustamante, 2011]pp. 87-88

Todo documento de embarque indica un consignatario, que, para efectos aduanales, es la persona autorizada para retirar la mercancía de la aduana. Así, debido al derecho que otorga la consignación de las mercancías, cuando un banco emite un crédito documentario, puede garantizarse el repago estableciéndose él mismo como parte a la que ha de designarse el documento de transporte. A esto se le llama emitir el crédito documentario con control.

Dada la negociación del crédito documentario por parte del beneficiario y una vez que el banco emisor recibe el pago por parte del ordenante de las negociaciones efectuadas, procede a 
Revista Economía y Administración, Vol. 9, No. 22018

endosar el documento a favor del ordenante [o de su agente aduanal, si así lo solicita el ordenante].

Para el control habrá que tomarse en cuenta lo siguiente:

1. Si el banco emisor decide aplicar el control, ha de tomar en cuenta que el crédito no deberá emitirse negociable contra copias sino contra originales, ya que estos son lo acreditativos de las mercancías al momento de retirarla de la aduana.

2. Se recomienda que se aplique el control solo en créditos documentarios disponibles a la vista. En un crédito a la vista el comprador debe pagar inmediatamente para recibir sus documentos $\mathrm{y}$, en consecuencia, poder retirar su mercancía de la aduana.

3. Existen por otra parte, situaciones en las que los bancos no deberían aplicar el control, como sería el caso que involucre la compra [importación] de mercancía perecedera, de fácil descomposición o de transporte, manejo o almacenamiento delicado porque en caso de que el ordenante no cumpla y el banco tome posesión de las mercancías, estas tardaran demasiado tiempo en venderse, antes de que perezcan. [Bustamante, 2011]pp. 88-89

Se han mencionado los documentos según los medios de transporte que operan en el comercio exterior de Honduras, pero al transportarse mercancía de un país a otro existe el riesgo o el hecho de que ocurran percances que provoquen la pérdida total o parcial de la carga. En estos casos, para evitar la pérdida monetaria, el importador o exportador [según Incoterm] contrata un seguro que cubre el transporte de la mercancía. Para certificar la contratación de dicho seguro la compañía aseguradora extiende el documento de seguro y cobertura.

\section{Responsabilidad del banco, valor legal e idioma en los documentos}

- Con base a lo que se establece en el art. 34 de la UCP 600, los bancos no asumen responsabilidad por la autenticidad o valor legal de ninguno de los documentos que se 
UNA RELACIÓN ENTRE CARTAS CRÉDITO Y LOGÍSTICA INTERNACIONAL

Revista Economía y Administración, Vol. 9, No. 22018

soliciten en el crédito, ni por el contenido o descripción que ellos hagan de las mercancías, esto es, en cuanto a su valor, peso, cantidad, calidad, estado envase, embalaje, ni por los actos u omisiones de terceros[transportistas, aseguradores o consolidadores de carga].

- Sobre la autenticidad de los documentos, habrá que tomar en cuenta que lo que le da esta propiedad es el sello, el cual debe no deberá ser una copia. A diferencia de las firmas, que si lo podrán ser.

- $\quad$ Según el art. 24 de la $\mathrm{ISBP}^{7}$, el idioma de los documentos deberá ser el mismo del de la carta de crédito. [Bustamante, 2011]pp.
En la siguiente tabla se explica, e forma detallada el proceso de contratación del servicio de carta de crédito, haciendo una relación con la logística internacional, en la compraventa de mercancía de un importador ubicado en Honduras y un exportador ubicado en otro país.

Tabla No. 1 Proceso contratación cartas de crédito de importación y relación con logística internacional.

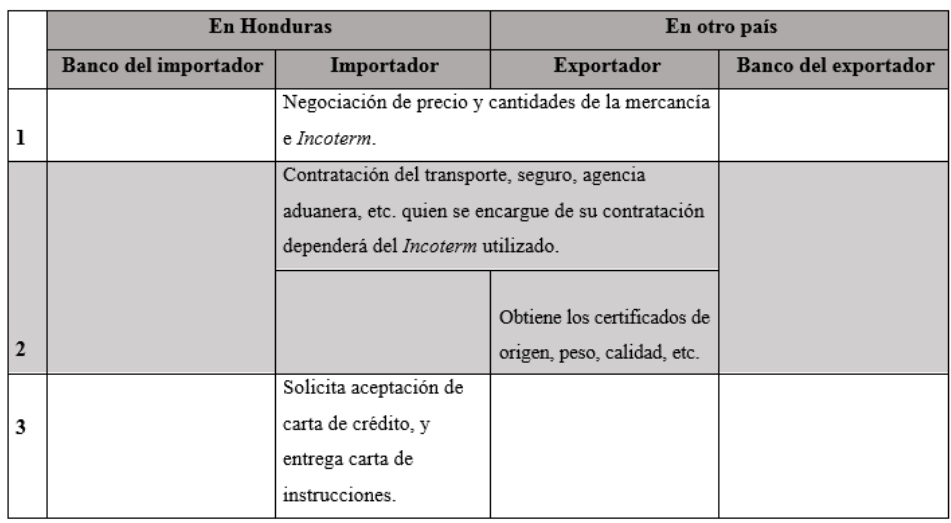

${ }^{7}$ International Standard Banking Practice [ISBP]: El ISBP, que fue revisado en 2007 como ISBP 681, se acredita con la que reduce drásticamente el número de discrepancias entre los bancos que se ocupan de los créditos documentarios. El ISBP aborda una serie de temas, por ejemplo, los errores de mecanografía, cálculos matemáticos, letras de cambio y la forma en que se dibujan, descripción de las mercancías en las facturas y firma de los conocimientos de embarque, entre otros. A la luz de los comentarios de los usuarios, la Comisión Bancaria ha decidido tanto actualizar y ampliar la ISBP actual para disfrutar de una gama de nuevos temas - como la transferencia, modificaciones, etc., que no se cubren en ISBP 681. La nueva revisión será se refieren a la última revisión de la CPI de la UCP, UCP 600. 
UNA RELACIÓN ENTRE CARTAS CRÉDITO Y LOGÍSTICA INTERNACIONAL

Revista Economía y Administración, Vol. 9, No. 22018

Tabla No. 2 Proceso contratación cartas de crédito de importación y relación con logística internacional.

\begin{tabular}{|c|c|c|c|c|}
\hline & \multicolumn{2}{|c|}{ En Honduras } & \multicolumn{2}{|c|}{ En otro país } \\
\hline & Banco del importador & Importador & Exportador & Banco del exportador \\
\hline \multirow[b]{2}{*}{4} & $\begin{array}{l}\text { Acepta la carta de crédito } \\
\text { y recibe carta de } \\
\text { instrucciones. }\end{array}$ & & & \\
\hline & \multicolumn{2}{|c|}{ Llegan a común acuerdo según términos del crédito. } & & \\
\hline 5 & $\begin{array}{l}\text { Avisa a banco del } \\
\text { exportador sobre crédito a } \\
\text { su favor. }\end{array}$ & & & $\begin{array}{l}\text { Recibe el mensaje, más } \\
\text { la carta de instrucciones } \\
\text { y da aviso a exportador. }\end{array}$ \\
\hline 6 & & & $\begin{array}{l}\text { Entrega documentos a su } \\
\text { banco, según carta de } \\
\text { instrucciones y envía la } \\
\text { mercancía a país de } \\
\text { destino. }\end{array}$ & \\
\hline
\end{tabular}

Tabla No. 3 Proceso contratación cartas de crédito de importación y relación con logística internacional.

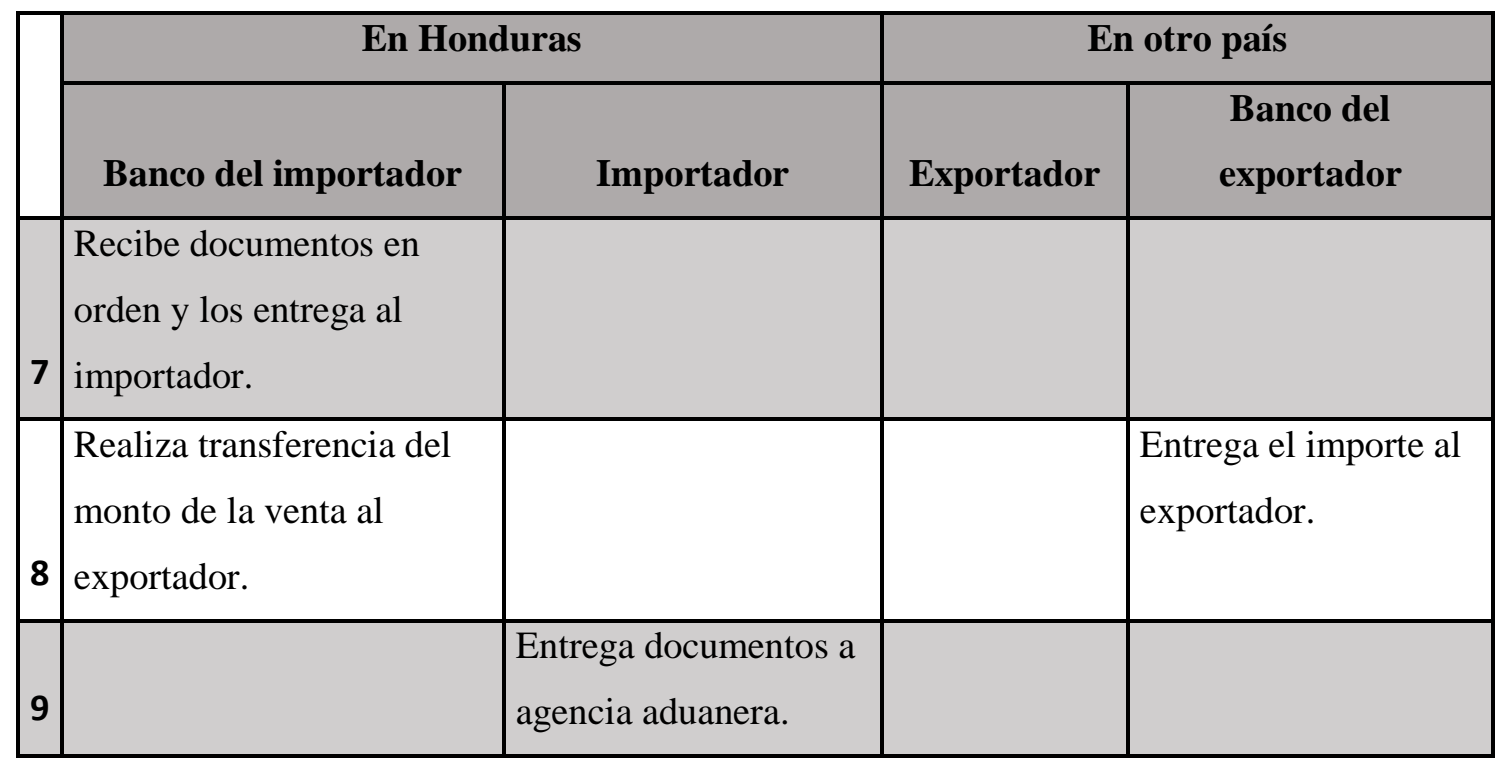




\section{UNA RELACIÓN ENTRE CARTAS CRÉDITO Y LOGÍSTICA INTERNACIONAL}

Revista Economía y Administración, Vol. 9, No. 22018

Tabla No. 4 Proceso contratación cartas de crédito de importación y relación con logística internacional.

\begin{tabular}{|c|c|c|c|c|}
\hline & \multicolumn{2}{|c|}{ En Honduras } & \multicolumn{2}{|c|}{ En otro país } \\
\hline & Banco del importador & Importador & Exportador & $\begin{array}{c}\text { Banco del } \\
\text { exportador }\end{array}$ \\
\hline 10 & \multicolumn{4}{|c|}{$\begin{array}{l}\text { La agencia aduanera envía un representante a la aduana, quien realiza el procedimiento de declaración } \\
\text { de mercancías, para su posterior levante, presentando la documentación exigible y realizando el pago } \\
\text { de tributos, según control aduanero. }\end{array}$} \\
\hline 11 & \multicolumn{4}{|c|}{ Se realiza el transporte de la mercancía, desde aduana hacia predios del importador. } \\
\hline
\end{tabular}

Fuente: construcción propia, con información de las páginas web de Bac Honduras y Banco Davivienda, 2017

\section{CONCLUSIÓN}

En este artículo se expuso la relación directa entre logística internacional y el servicio financiero internacional de cata de crédito, la cual se detalla en el cuadro anterior, tomando en cuenta, principalmente:

- Si la mercancía llega a destino y el banco de importador no ha efectuado el pago, dicha mercancía, no será retirada de la aduana.

- El pago se hará hasta que la documentación [también vista por el banco del exportador] este en manos del importador.

- En las aduanas, como comprobante de transferencia bancara entre los bancos del importador y exportador, se puede presentar información por parte del SWIFT.

- Las empresas de transporte de documentación [curier] son las que reciben los documentos por parte del banco del exportador y la hacen llegar al importador.

Un profesional, tanto en financiación del comercio o en logística, debe tener conocimiento y de debe aplicar médicas y procedimientos, referentes a la relación que existe entre estas dos disciplinas del comercio internacional, habiendo también interrelaciones entre otras ramas del comercio. 
UNA RELACIÓN ENTRE CARTAS CRÉDITO Y LOGÍSTICA INTERNACIONAL

Revista Economía y Administración, Vol. 9, No. 22018

\section{REFERENCIAS BIBLIOGRÁFICAS}

Anaya, R. (2010). Los 6 aspectos teóricos y prácticos del comercio internacional. [en línea]. Disponible en:http://www.gestiopolis.com/6aspectos-teoricos-practicos-comerciointernacional/[2016, 2 de diciembre].

Bac Honduras, (2015). Servicios internacionales. [en línea]. Disponible en:

https://www.bac.net/honduras/esp/banc o/empre/bacemp.html[2015, 11 de diciembre].

Banco Davivienda, (2015). Comercio exterior. [en línea]. Disponible en: http://www.davivienda.com.hn/banco/e mpresas/productos-paraempresas/comercio-exterior [2016, 14 de noviembre].

Bustamante, M. (2011). Los créditos documentarios en el comercio internacional. (4a. ed.). México: Trillas. ICC, (2010). The Incoterms rules. [en línea]. Disponible en: http://www.iccwbo.org/productsandservices/tradefacilitation/incoterms2010/the-incoterms-

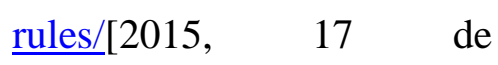
noviembre]
Levy, S. (2015). Globalización económica.México: ISEF. [en línea]. Disponible en:www.sarylevy.com/docs/03-1999--GlobFzasDes\%20RVAC.pdf[2017, 4 de junio].

Molins, A. (2011). Introducción a la logística internacional. Santiago de Compostela.

NI Business, (2016). Letters of credit.[en línea]. Disponible en: https://www.nibusinessinfo.co.uk/conte nt/uniform-customs-and-practicedocumentary-credit [2017, 4 de abril]. Nunes, P. (2012). Actividades de financiación. [en línea]. Disponible en:http://old.knoow.net/es/cieeconcom/c ontabilidad/actividadesfinanciacion.htm [2017, 10 de enero].

Pritchard, J. (2016). Standby Letter of Credit.[en línea]. Disponible en:http://banking.about.com/od/Letters

OfCredit/fl/Standby-Letter-ofCredit.htm[2017, 11 de julio].

SIECA, (2008). Código aduanero uniforme

centroamericano.http://www.sieca.int/P ortalData/Documentos/C39E471D-

14C9-4C72-9202-

7A26DC694AE9.pdf $[2016, \quad 11$ de enero].

Solano,L. (2014). Incoterms2010[en línea]. Disponible en:http://repositorio.promperu.gob.pe/re 
UNA RELACIÓN ENTRE CARTAS CRÉDITO Y LOGÍSTICA INTERNACIONAL

Revista Economía y Administración, Vol. 9, No. 22018

positorio/handle/123456789/572 [2017,

05 de marzo].

The Best-Run Businesses Run SAP, (2015). Escenario: Exportaciones que implican una carta de crédito documentario. [en línea]. Disponible en:http://help.sap.com/saphelp_470/help data/es/a2/28abc7abc311d395750000e8 3dcfd4/content.htm [2017, 7 de junio].

UPS, (2016). Soporte-lista de empaque.

[en línea]. Disponible en: https://www.ups.com/content/hn/es/reso urces/sri/packing-list.html\#top[2016, 11 de enerol.

Zorrilla, J. (2004). Servicios financieros para el comercio internacional. [en línea]. Disponible en:

http://www.gestiopolis.com/servicios-

financieros-comercio-

internacional/[2017, 7 de junio]. 